\title{
Low expression of Ku70/80, but high expression of DNA-PKes, predict good response to radiotherapy in early breast cancer
}

\author{
KARIN SÖDERLUND LEIFLER ${ }^{1}$, SIV QUESETH ${ }^{1}$, TOMMY FORNANDER ${ }^{2}$ and MARIE STENMARK ASKMALM ${ }^{1}$ \\ ${ }^{1}$ Linköping University, Department of Clinical and Experimental Medicine, Division of Surgery and Clinical Oncology, \\ Linköping; ${ }^{2}$ Karolinska University Hospital, Department of Oncology, Stockholm, Sweden
}

Received May 25, 2010; Accepted July 9, 2010

DOI: 10.3892/ijo_00000808

\begin{abstract}
The purpose was to study the prognostic and predictive roles of DNA protein kinase catalytic subunit (DNA-PKcs), Ku70/80 and p53 for the effect of radiotherapy in breast cancer patients. Protein expressions of $\mathrm{Ku} 70 / 80$, DNA-PKcs and p53 were examined using immunohistochemistry in tumours from 224 breast cancer patients, who were randomised to receive post-operative radiotherapy or adjuvant chemotherapy (cyclophosphamide, methotrexate, 5-fluorouracil). One hundred and twenty-nine $(60 \%)$ of the tumours had low expression of Ku70/80, 122 (57\%) had low expression of DNA-PKcs and 65 (30\%) had altered p53 expression. None of the proteins were indicative to the prognosis of local recurrence-free survival. Even though the expression of Ku70/80 and DNA-PKcs correlated well, they were not associated with treatment outcome in the same way. Low expression of $\mathrm{Ku} 70 / 80$ predicted good effect of radiotherapy $(\mathrm{RR}=0.31,95 \% \mathrm{CI} 0.13-0.76, \mathrm{p}=0.01)$. In contrast, the greatest benefit of radiotherapy over chemotherapy was seen in patients with high DNA-PKcs expression $(\mathrm{RR}=0.25$, 95\% CI 0.07-0.84, $\mathrm{p}=0.02$ ). Altered p53 expression predicted poor response to radiotherapy. We believe that the results reflect the different roles of DNA-PKcs and Ku70/80 in repair and cell death regulation after DNA damage. These differences could be of importance when developing drugs that target DNA repair.
\end{abstract}

\section{Introduction}

A majority of patients with locally advanced breast cancer are treated with adjuvant radiotherapy (RT) to reduce the risk of locoregional recurrence and possibly prolong breast cancer-specific survival (1). However, there is a need for

Correspondence to: Dr Marie Stenmark Askmalm, University Hospital, Department of Oncology, Regional Oncogenetic Clinic, SE-581 85 Linköping, Sweden

E-mail: marie.askmalm@lio.se

Key words: radiotherapy, breast cancer, DNA-PK, Ku70/80, p53 markers that can predict which patients are likely to benefit from radiotherapy.

The efficiency of DNA damage repair is one of the most important determinants of radiation sensitivity (2). Other factors that influence radiosensitivity are hypoxia (3), cell cycle phase (4), and possibly also the ability of the tumour cells to undergo apoptosis $(5,6)$. Several of these factors are linked to the molecular profile of tumour cells. Ionising radiation (IR) employed in radiotherapy induces different types of damage, of which the double-strand breaks show the best correlation with the level of cell killing (reviewed in ref. 7). Double-strand breaks are repaired by two distinct, but sometimes overlapping, mechanisms: non-homologous endjoining (NHEJ) and homologous recombination (HR). Homologous recombination is an essentially error-free process acting predominantly in the late $\mathrm{S}$ and $\mathrm{G}_{2}$ phases of the cell cycle, in which a homologous template is used to ensure correct restoration of the damaged DNA sequence (8). In contrast, NHEJ is a more approximate repair mechanism. During NHEJ the broken ends are resected or processed, with potential loss of nucleotides at the repair site, and the back bones are subsequently ligated.

One of the key players in NHEJ is DNA-dependent protein kinase (DNA-PK). It is a complex consisting of DNA-PK catalytic subunit (DNA-PKcs) and a regulatory heterodimer of $\mathrm{Ku} 70$ and $\mathrm{Ku} 80$ (or Ku86), which are constitutively expressed at relatively high levels in cells (9). The $\mathrm{Ku}$ heterodimer binds to DNA ends with high affinity independently of DNA sequence (10). Ku recruits DNA-PKcs to the DNA and the interaction between $\mathrm{Ku}$ and DNA-PKcs stimulates the catalytic potential of the DNA-PK complex (11). To date, $>20$ proteins have been reported to be substrates of DNA-PK, including AKT/PKB, Artemis, XRCC4 and p53 (12,13).

The DNA-PKcs gene is defect in mice with severe combined immunodeficiency syndrome (SCID) (14). The scid mutation confers immunodeficiency and radiation hypersensitivity due to deficiencies in the processing of DSB intermediates during development of the immune system and DNA repair. Similarly, mice with mutated $K u 70$ also display defect DNA repair and hypersensitivity to ionising radiation (15). Furthermore, experimental studies have shown that inhibition of DNA-PK cause radiosensitisation in vitro and in vivo (16-19). This is in line with the central role of the DNA-PK complex in DNA repair, and forms the basis of 
pharmacological inhibitors that might become useful in cancer therapy in the future.

In recent years, the picture has become more complicated, with several studies pointing toward a role for these proteins in apoptotic signalling. It has been demonstrated that DNAPK activates the pro-survival kinase AKT/PKB after lower doses of IR (1-10 Gy), but not after a lethal dose of $30 \mathrm{~Gy}$ (20). Ku70 can suppress Bax-mediated apoptosis (21). On the other hand, DNA-PKcs phosphorylates and activates the tumour suppressor p53, the gene of which is mutated or deleted in many cancers, including breast cancer $(22,23)$. p53 is important in the cellular response to ionising radiation by regulating cell cycle checkpoint control, inducing apoptosis and possibly by modulating DNA repair. Several clinical studies indicate that the presence of mutated p53 or lack of p53 function is associated with decreased local tumour control following radiotherapy; however, the results are not conclusive (24). The possibility to identify those tumours most likely to respond to radiotherapy in terms of local recurrence could be an important tool in the ambition to individualise the treatment of breast cancer patients further.

The aim of this study was to investigate protein expression of the DNA-PK complex components using immunohistochemistry. We examined whether DNA-PKcs and the $\mathrm{Ku} 70 / 80$ heterodimer are related to prognosis and effect of radiotherapy in early breast cancer. If these proteins are required for efficient repair of double-strand breaks, reduced expression of these proteins in tumour cells ought to lead to increased sensitivity to ionising radiation. This would be reflected as improved local tumour control. We also wanted to investigate the possible influence of DNA-PKcs on p53, in terms of response to radiotherapy. To the best of our knowledge, the role of the DNA-PK complex in prognosis and prediction of radiotherapy has not been investigated in a clinical breast cancer material before.

\section{Material and methods}

Patients and tumours. In 1976, a prospective clinical trial that compared postoperative radiotherapy with adjuvant chemotherapy was initiated by the Stockholm Breast Cancer Study Group (25). The current study is performed on tumour material from a subset of 224 premenopausal women included in that trial. The subset of patients in the present study did not differ significantly from all the patients in the main study with regard to tumour and treatment characteristics (data not shown). Inclusion criteria were histologically verified lymph node metastases or a tumour diameter exceeding $30 \mathrm{~mm}$. After being surgically removed by modified radical mastectomy, tumours were fixed in formalin and embedded in paraffin. Patients were randomised to receive radiotherapy or chemotherapy. Individually dose-planned postoperative radiotherapy was given with a high-voltage technique at a total dose of 46 Gy, with 2 Gy per fraction 5 days a week. The target volume included the chest wall, axilla, Supraclavicular fossa and the ipsilateral internal mammary nodes. Chemotherapy was given according to the first Milan trial protocol, with 12 courses of CMF (cyclophosphamide $100 \mathrm{mg} / \mathrm{m}^{2}$ orally on days $1-14$, methotrexate $40 \mathrm{mg} / \mathrm{m}^{2}$ i.v. on days 1 and 8,5 -fluorouracil $600 \mathrm{mg} / \mathrm{m}^{2}$ i.v. on days 1 and 8 ). In 1988, the protocol was changed to six courses of CMF instead of 12. The median follow-up time was 13.1 years. Fifty-one patients experienced histologically verified local recurrence and 114 had distant recurrence. Patients have given their informed consent regarding participation in the randomised study. The use of human tissue for retrospective analysis of prognostic and predictive factors was approved by the local ethics committee.

DNA-PKcs and Ku70/80 immunohistochemical staining. Tissue microarray blocks with triplicate samples from each tumour were constructed using a Tissue Microarrayer (Beecher Instruments, Sun Prairie, WI, USA) as previously described (26). DNA-PKcs antigen retrieval was performed by heating in citrate buffer ( $\mathrm{pH}$ 6.0) in an incubator at $78^{\circ} \mathrm{C}$ for $24 \mathrm{~h}$. Antigen retrieval was not necessary for the $\mathrm{Ku} 70 / 80$ epitope. Endogenous peroxidase activity was blocked by $3 \%$ hydrogen peroxide $\left(\mathrm{H}_{2} \mathrm{O}_{2}\right) /$ methanol. Primary mouse monoclonal antibodies (Neomarkers, Fremont, CA) against DNA-PKcs (Ab-3, clone 42-psc, directed against amino acids 2713-3198 of the 4128 residues in the protein) and $\mathrm{Ku}(\mathrm{p} 70 / \mathrm{p} 80)$ (Ab-3, clone 162 , that recognises a conformational epitope of the heterodimer) were used at a concentration of $2 \mu \mathrm{g} / \mathrm{ml}$. Antibody incubations were performed at room temperature; the DNAPKcs antibody for $2 \mathrm{~h}$ and the Ku70/80 antibody for $30 \mathrm{~min}$.

After washing, slides were incubated with Dako EnVision ${ }^{+}$Mouse (Dako, Carpinteria, CA) for $30 \mathrm{~min}$ at room temperature. Positively stained cells were visualised with 3'-diaminobenzidine tetrahydrochloride (DAB) solution, counterstained with haematoxylin and the slides were mounted. As negative controls mouse IgG1 or IgG2a isotype-matched irrelevant antibodies (Sigma, St. Louis, MO) were used at the same dilutions as the corresponding primary antibodies. Slides with tonsil tissue were used as positive controls for staining (Neomarkers). Slides with normal, unmatched breast tissue were stained together with the tissue microarray slides.

Staining, which was nuclear for both DNA-PKcs and $\mathrm{Ku} 70 / 80$, was evaluated visually and independently by two investigators. Tumours were grouped according to the percentage of tumour cells with positive staining: negative, 1-25, 26-50, 51-75 and 76-100\%. In addition, staining intensity was graded as negative, low, moderate or strong. In the statistical analyses, expression of DNA-PKcs and Ku70/80 were divided into low (0-75\% positive tumour cells) or high (76-100\% positive tumour cells). A cut-off level around $75 \%$ positive cells has been used in several previous studies (27-31).

p53 immunohistochemical staining. Slides were pretreated with $1 \mathrm{mM}$ EDTA/Tris buffer ( $\mathrm{pH} \mathrm{9.0)} \mathrm{and} \mathrm{heated} \mathrm{for} 40 \mathrm{~min}$ in high temperature waterbath $\left(96-98^{\circ} \mathrm{C}\right)$. Staining of p53 was performed using a TechMate $500^{+}$Instrument (Dako) according to protocol by the manufacturer, using a mouse monoclonal p53 antibody (clone DO-7, Dako) at dilution 1:100 and Dako EnVision Detection Kit, peroxidase/DAB, rabbit/mouse (Dako). Slides were counterstained with haematoxylin, dehydrated in graded ethanol and mounted.

Nuclear p53 staining in tumour cells was visually evaluated by two independent investigators. Staining intensity was graded as negative, weak or strong, and the percentage of stained cells was categorised into six groups: negative, $<10$, $10-25,26-50,51-75$ and $76-100 \%$. Tumours that had strong 
DNA-PKcs
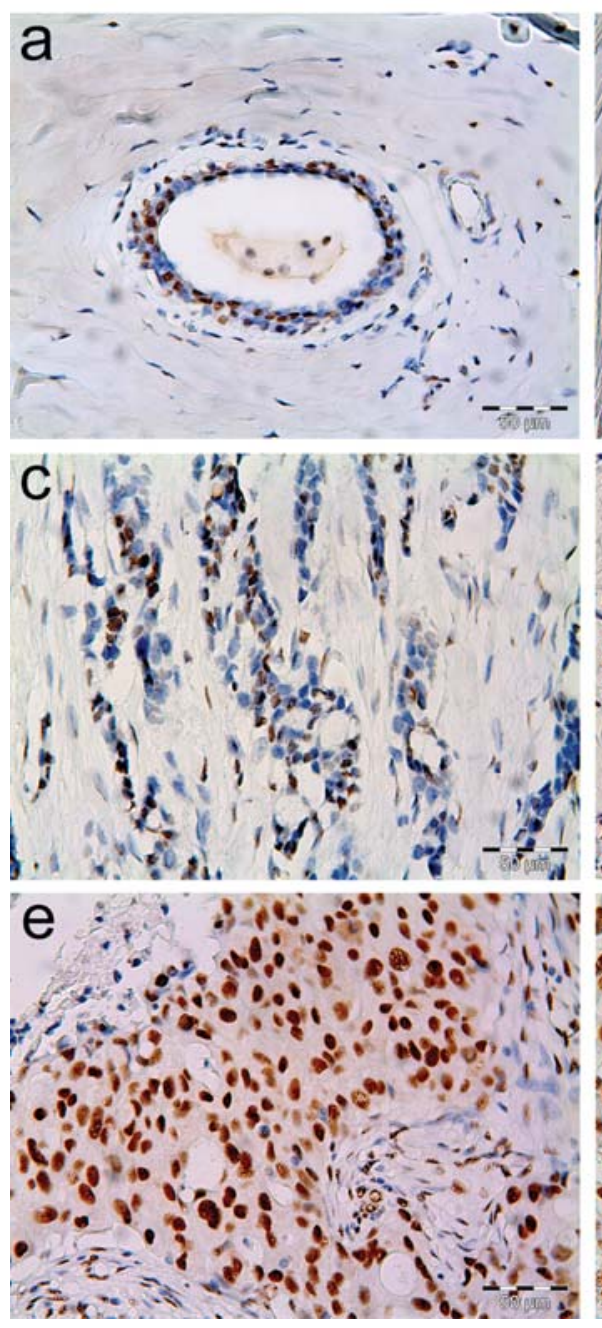

Ku70/80
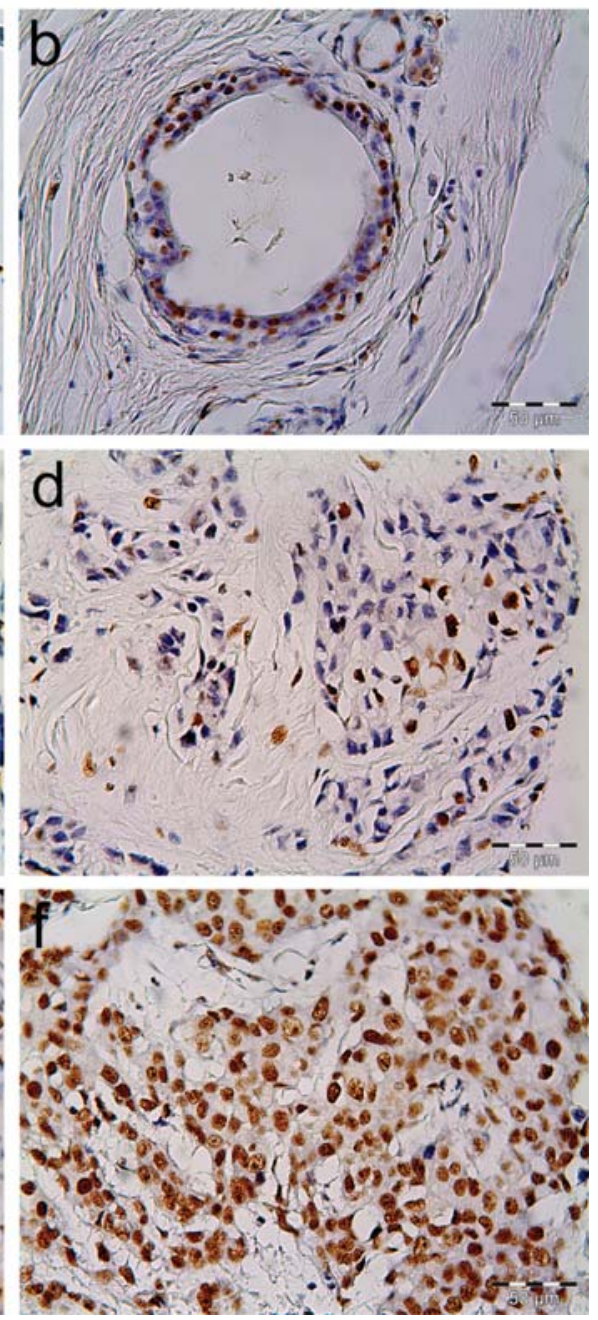

Figure 1. Immunohistochemical staining of DNA-PKcs and Ku70/80 in normal breast (a-b), low expression in breast tumour (c-d) and high expression in tumour (e-f). Original magnification $\mathrm{x} 400$. Scale bar in lower right corner shows $50 \mu \mathrm{m}$.

staining in $>10 \%$ of the cells were considered to have altered p53.

Statistical analysis. Relationships between variables were assessed by the $\chi^{2}$-test. Estimation of the probabilities of recurrence-free survival was performed with the KaplanMeier product limit method. Relative rate (RR) and p-values of recurrence were estimated using Cox's proportional hazard regression. Univariate analysis of local recurrence-free survival in relation to protein expression was analysed in the CMF-treated patient group only (prognosis). Variables included in multivariate analyses were histologic grade as estimated by the Nottingham grading system (NHG 1-3), tumour size ( $\leq 20 \mathrm{~mm}$ or $>20 \mathrm{~mm}$ ), number of positive lymph nodes, oestrogen receptor (ER) expression (cut-off value 0.1 fmol $/ \mu \mathrm{g} \mathrm{DNA}$ ) and treatment modality (CMF/radiotherapy). Interaction tests were performed as a Cox analysis, which included the covariates $x$, treatment and the interaction term $x^{*}$ treatment. $\mathrm{p}$-values of $\leq 0.05$ were considered statistically significant. All statistical analyses were made using Statistica software version 7.1 (Statsoft, Tulsa, OK, USA). Of the 224 tumours, 8 were missing from the Ku70/80 staining, 9 from DNA-PKcs staining and 9 from p53 staining.

\section{Results}

Expression of Ku70/80 and DNA-PKcs in normal breast and breast tumours. Normal breast epithelium showed strong staining intensity for both Ku70/80 and DNA-PKcs in 26$50 \%$ of epithelial cells (Fig. 1). When divided according to percentage of positive cells with a cut-off at 75\%, $129(60 \%)$ tumours were categorised as having low expression of $\mathrm{Ku} 70 / 80$ and $122(57 \%)$ had low expression of DNA-PKcs (Table I). The expression of DNA-PKcs and the Ku70/80 heterodimer were strongly correlated $(\mathrm{p}<0.001)$. Sixty-five $(30 \%)$ of the tumours had altered p53 expression.

Prediction of treatment outcome. Radiotherapy significantly decreased the risk of local recurrence as compared to chemotherapy $(\mathrm{p}=0.04)$, as previously reported for this material (26). The greatest benefit of radiotherapy was seen in patients whose tumours had low expression of Ku70/80 ( $R R=0.31$, 
Table I. Distribution of staining intensity and fraction of positively stained cells of DNA-PKcs, Ku70/80 and p53 in breast tumours.

\begin{tabular}{|c|c|c|c|c|}
\hline & DNA-PKcs & $\mathrm{Ku} 70 / 80$ & & p53 \\
\hline Intensity & & & Intensity & \\
\hline Negative & $2(1)$ & $13(6)$ & Negative & $33(15)$ \\
\hline Weak & $15 \quad(7)$ & $43(20)$ & + & $106(49)$ \\
\hline Moderate & $55(25)$ & $63(29)$ & ++ & $76(35)$ \\
\hline Strong & $143(67)^{\mathrm{a}}$ & $100(46)^{\mathrm{a}}$ & Missing & 9 \\
\hline Missing & 9 & 8 & & \\
\hline$\%$ positive nuclei & & & $\%$ positive nuclei & \\
\hline Negative & $2(1)$ & $13(6)$ & Negative & $33(15)$ \\
\hline $1-25$ & $10 \quad(5)$ & $17 \quad(8)$ & $<10$ & $66(31)$ \\
\hline $26-50$ & $31(14)^{\mathrm{a}}$ & $28(13)^{\mathrm{a}}$ & $10-25$ & $34(16)$ \\
\hline $51-75$ & $79(37)$ & $71(33)$ & $26-50$ & $26(12)$ \\
\hline $76-100$ & $93(43)$ & $87(40)$ & $51-75$ & $19(9)$ \\
\hline \multirow[t]{2}{*}{ Missing } & 9 & 8 & $76-100$ & 37 (17) \\
\hline & & & Missing & 9 \\
\hline
\end{tabular}

aStaining pattern in normal breast (not available for p53). Values in parentheses represent percentage.
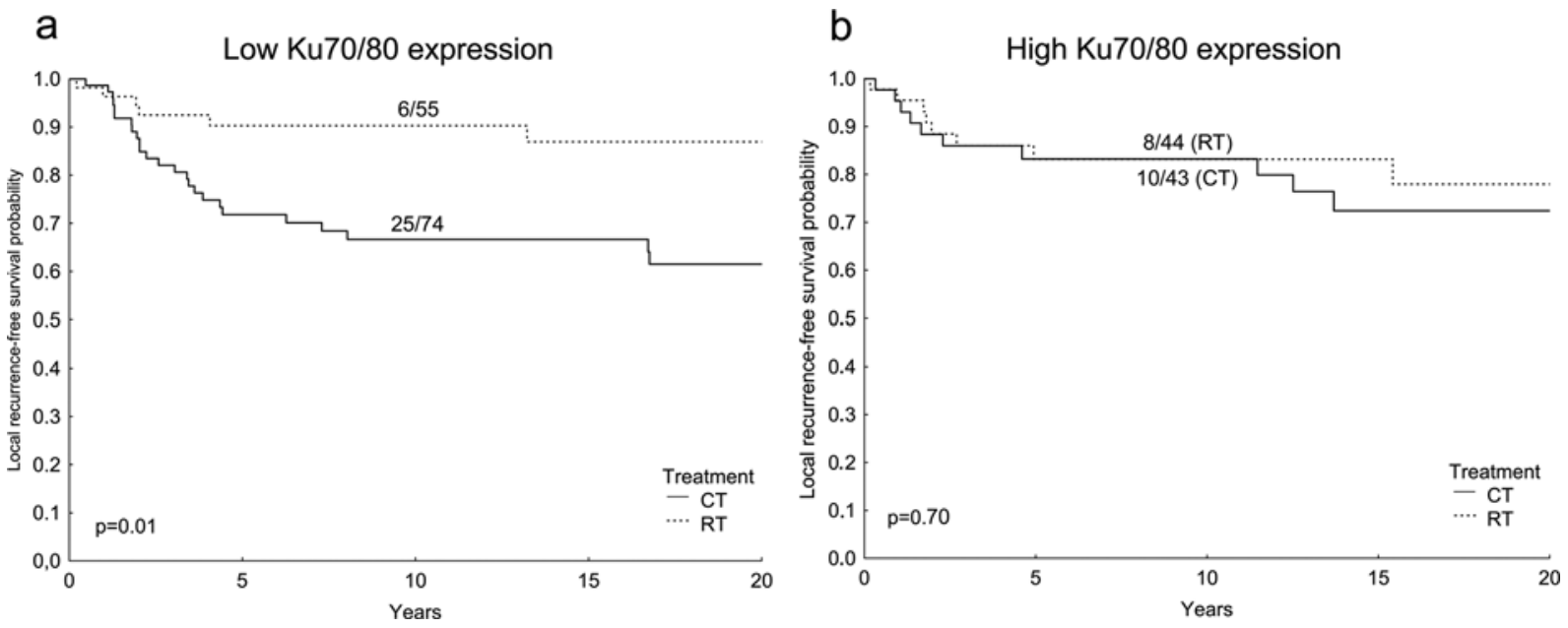

Figure 2. Local recurrence-free survival in breast cancer patients treated with RT (dotted line) as compared to CT (solid line) in relation to low (a) and high (b) expression of the Ku70/80 heterodimer. Numbers represent events (local recurrences) per total number of patients in each group. RT, radiotherapy; CT, chemotherapy (cyclophosphamide, methotrexate and 5-fluorouracil).

95\% CI 0.13-0.76, $\mathrm{p}=0.01)$, whereas there was no benefit from radiotherapy over chemotherapy in patients with high expression $(\mathrm{RR}=0.80,95 \%$ CI 0.31-2.02, $\mathrm{p}=0.63)$ (Fig. 2). In contrast, patients whose tumours had low expression of DNA$\mathrm{PKcs}$ had no significant benefit of radiotherapy $(\mathrm{R} R=0.65$, 95\% CI 0.31-1.40, $\mathrm{p}=0.27$ ), but in patients with high DNAPKcs expression the risk of local recurrence was significantly lower with radiotherapy as compared to chemotherapy ( $R R=0.25,95 \%$ CI 0.07-0.84, p=0.02) (Fig. 3). The interaction variables $\mathrm{Ku} 70 / 80 * \mathrm{RT}$ and DNA-PKcs*RT were not statistically significant in interaction tests $(\mathrm{p}=0.15$ and $\mathrm{p}=0.18$, respectively). Similar results were obtained if the expression was evaluated in terms of staining intensity; in other words, negative-weak staining of $\mathrm{Ku} 70 / 80$ but moderate-strong staining of DNA-PKcs was related to benefit of radiotherapy (data not shown).

In terms of p53 status, there was a significant difference in the effect of radiotherapy on local tumour control as compared with chemotherapy in patients whose tumours had normal expression of $\mathrm{p} 53$ ( $\mathrm{RR}=0.42,95 \%$ CI $0.19-0.90$, $\mathrm{p}=0.03$ ) (Fig. 4). This benefit of radiotherapy was not seen in patients with altered p53 $(\mathrm{RR}=1.04,95 \%$ CI 0.39-2.79, $\mathrm{p}=0.94)$. The interaction between $\mathrm{p} 53$ status and RT was not statistically significant $(\mathrm{p}=0.15)$.

We also examined the relation between DNA-PKcs expression and p53 status on the response to radiotherapy. In the subgroup of patients with normal p53 in their tumours, there was a borderline significant benefit of radiotherapy if the tumour at 
a

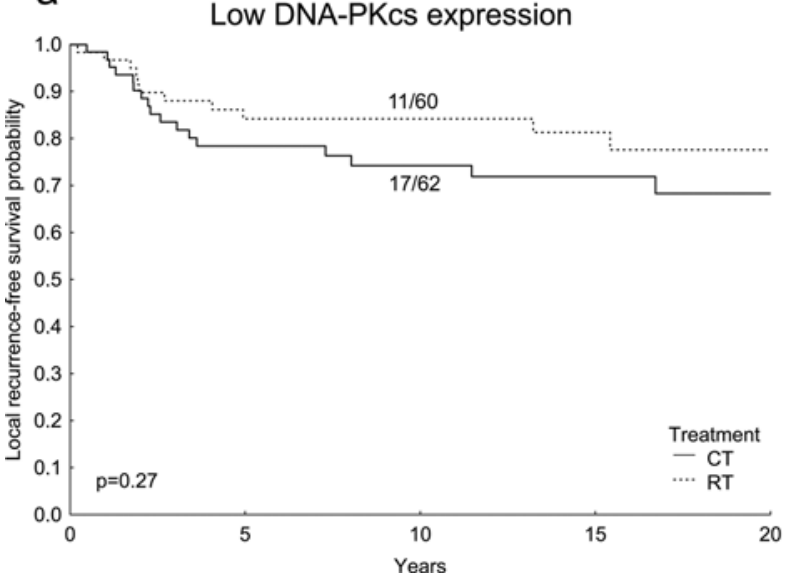

b

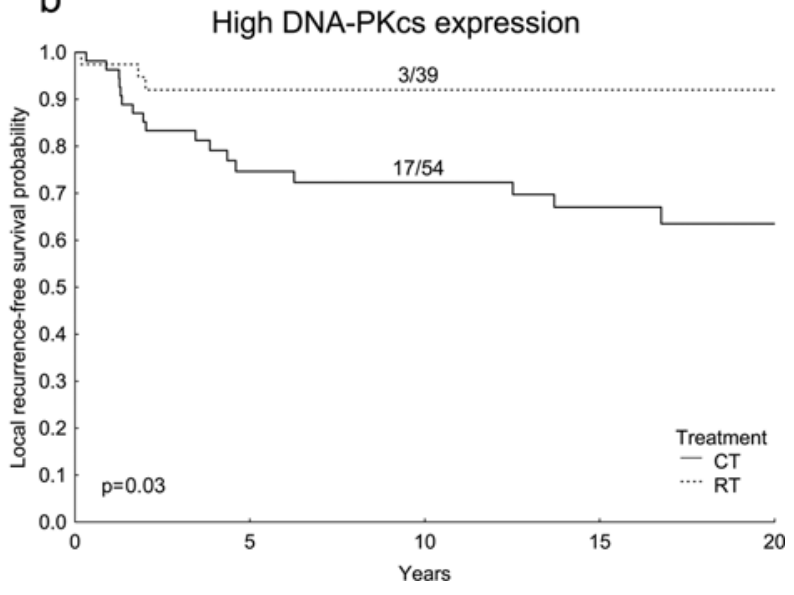

Figure 3. Probability of local recurrence-free survival in patients treated with RT (dotted line) and CT (solid line) in relation to low (a) and high (b) expression of DNA-PKcs protein. Numbers represent events (local recurrences) per total number of patients in each group. RT, radiotherapy; CT, chemotherapy (cyclophosphamide, methotrexate and 5-fluorouracil).
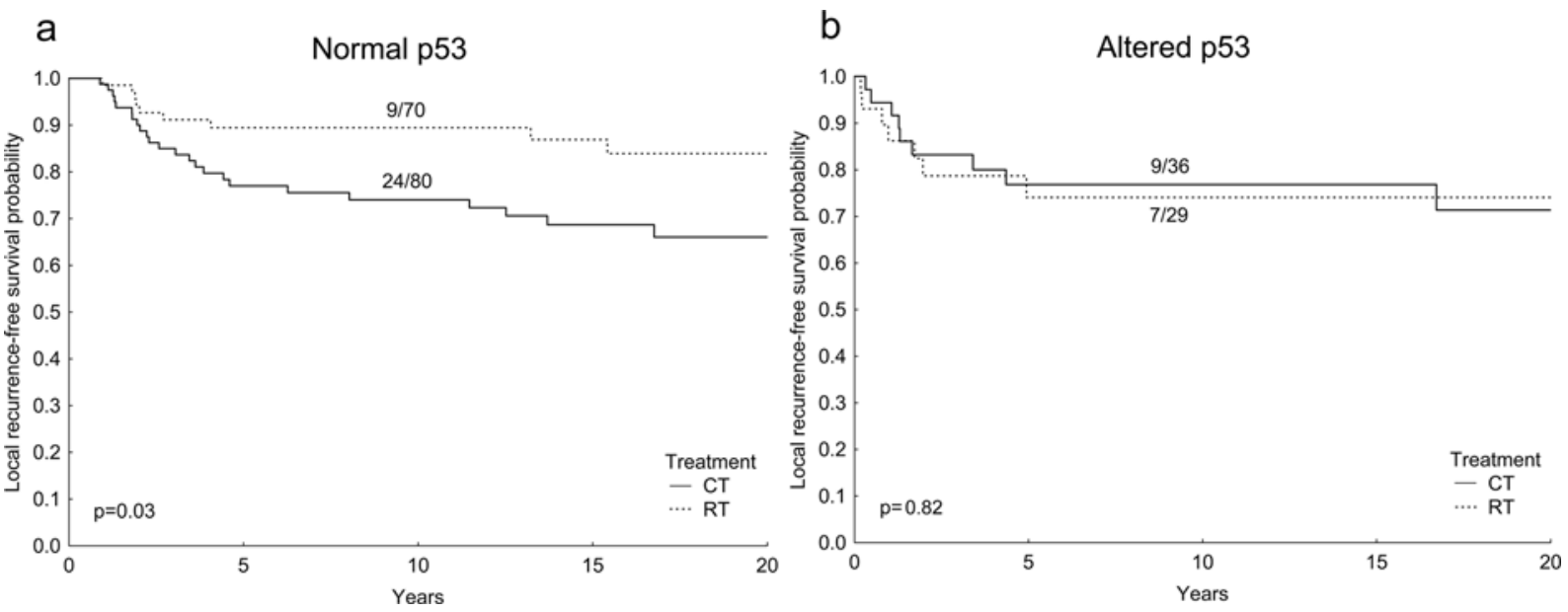

Figure 4. Local-recurrence-free survival in patients treated with RT (dotted line) and CT (solid line) in relation to p53 status. Numbers represent events (local recurrences) per total number of patients in each group. RT, radiotherapy, CT, chemotherapy (cyclophosphamide, methotrexate and 5-fluorouracil).

the same time showed high expression of DNA-PKcs $(\mathrm{RR}=0.22$, 95\% CI 0.05-1.02, p=0.05) (Fig. 5a). The effect of radiotherapy on tumours with normal p53 was not significant in tumours with low DNA-PKes expression ( $\mathrm{RR}=0.47,95 \%$ CI 0.18 $1.26, \mathrm{p}=0.13$ ) (Fig. 5c), nor in tumours with altered p53 (high DNA-PKcs: $R R=0.41,95 \%$ CI 0.05-3.54, $\mathrm{p}=0.42$; low DNAPKcs: $R R=1.37,95 \%$ CI 0.37-5.15, p=0.64) (Fig. 5b and d). The subgroup with normal p53 benefitted significantly from radiotherapy if the tumour also expressed low levels of $\mathrm{Ku} 70 /$ $80(\mathrm{RR}=0.28,95 \% \mathrm{CI} 0.09-0.83, \mathrm{p}=0.02)$, but not if $\mathrm{Ku} 70 / 80$ expression was high $(\mathrm{RR}=0.53,95 \% \mathrm{CI} 0.16-1.83, \mathrm{p}=0.32)$.

Correlation to prognostic markers and prognosis. High expression of $\mathrm{Ku} 70 / 80$ was correlated to ER positivity ( $\mathrm{p}=0.02$ ). High expression of DNA-PKcs correlated with high histologic grade and large tumour size $(\mathrm{p}=0.02$ and $\mathrm{p}=0.05)$. Altered p53 correlated to high histologic grade $(\mathrm{p}<0.001)$ and oestrogen receptor negativity $(\mathrm{p}=0.002)$.

In univariate analysis, expression of $\mathrm{Ku} 70 / 80$ was not related to the prognosis of local recurrence-free survival of the patients $(\mathrm{RR}=0.66,95 \% \mathrm{CI} 0.32-1.38, \mathrm{p}=0.27)$, neither was the expression of DNA-PKcs $(\mathrm{RR}=1.16,95 \%$ CI $0.59-2.28$, $\mathrm{p}=0.66$ ). Similarly, there was no significant relation between altered expression of p53 and probability of local recurrence ( $\mathrm{RR}=0.90,95 \%$ CI $0.42-1.95, \mathrm{p}=0.80)$. Treatment modality and positive lymph nodes were prognostic factors associated with risk of local recurrence in both uni- and multivariate analysis, whereas for distant recurrence tumour size and lymph node status were prognostic factors (Table II).

\section{Discussion}

In this study, low protein expression of the Ku70/80 heterodimer predicted good response to radiotherapy in early breast cancer. Even though the expression of Ku70/80 and DNAPKcs were highly correlated, the different components in the DNA-PK complex did not influence treatment outcome in the same way. Somewhat surprisingly, it was high expression of DNA-PKcs, and not low expression, that was related to a significant benefit of radiotherapy in this material.

The difference that we observed between Ku70/80 and DNA-PKcs might be a result by chance; however, it is possible 
a
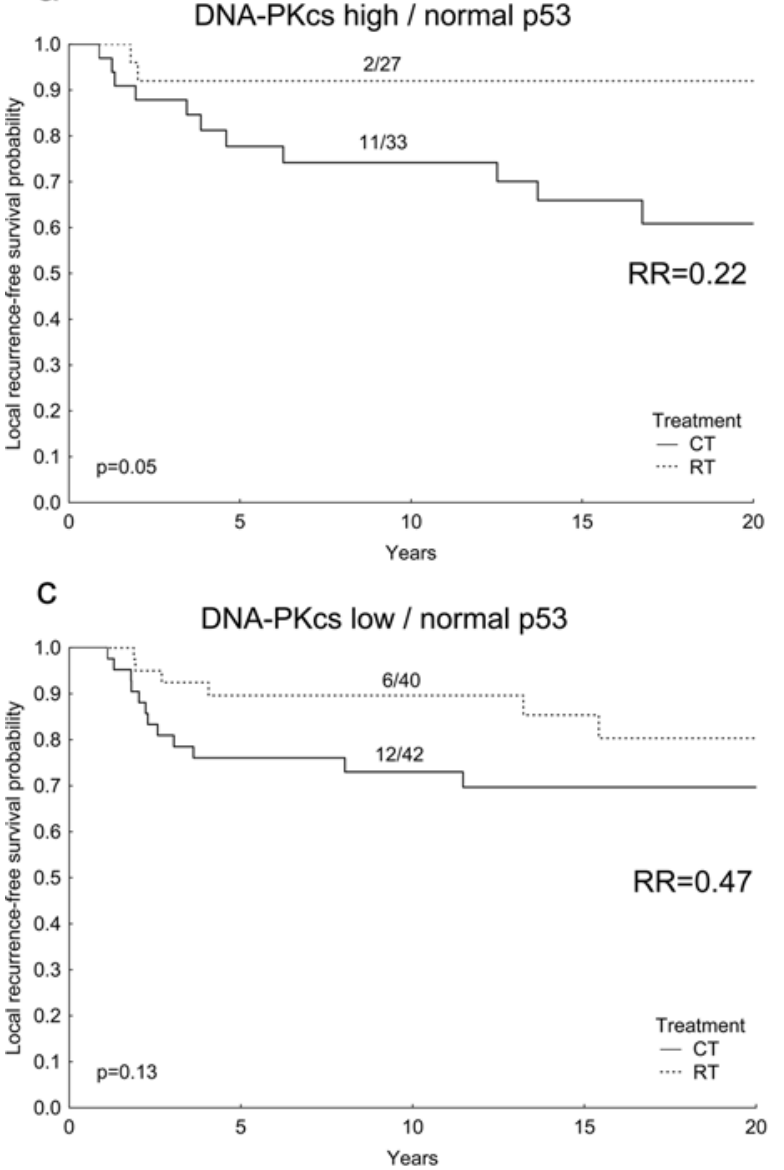
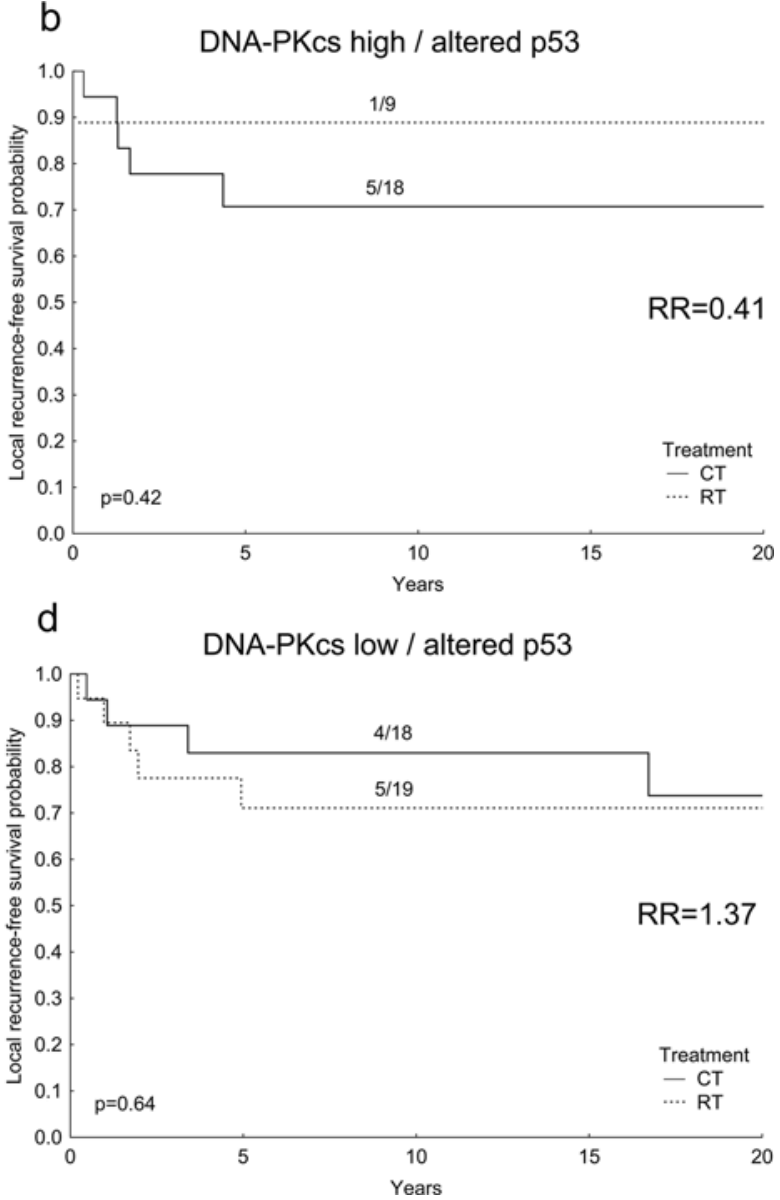

Figure 5. Probability of local recurrence-free survival in relation to the combined expression of DNA-PKcs and p53. Estimates of relative risk refer to RT as compared to CT. The variables were coded 0 (CT) and 1 (RT) and risks were estimated by Cox's proportional hazards model. Numbers represent events (local recurrences) per total number of patients in each group. RT, radiotherapy; CT, chemotherapy (cyclophosphamide, methotrexate and 5-fluorouracil).

Table II. Multivariate analysis of local and distant relapse including prognostic factors and treatment modality.

\begin{tabular}{lllll}
\hline \multirow{2}{*}{ Variable } & \multicolumn{2}{c}{ Local recurrence } & \multicolumn{2}{c}{ Distant recurrence } \\
\cline { 2 - 3 } & RR $(95 \%$ CI $)$ & p-value & RR $(95 \%$ CI $)$ & $1.12(0.75-1.67)$ \\
Treatment & $0.41(0.20-0.84)$ & 0.015 & $1.36(0.98-1.89)$ & 0.59 \\
Tumour grade & $1.53(0.90-2.61)$ & 0.12 & $1.74(1.27-2.40)$ & 0.069 \\
Positive lymph nodes & $1.92(1.13-3.27)$ & 0.0017 & $1.58(1.02-2.44)$ & 0.00066 \\
Tumour size & $1.22(0.62-2.40)$ & 0.56 & $1.72(0.47-1.11)$ & 0.041 \\
ER status & $0.74(0.37-1.46)$ & 0.38 & $1.01(0.67-1.53)$ & 0.96 \\
DNA-PKcs & $0.92(0.47-1.81)$ & 0.81 & $0.98(0.65-1.48)$ & 0.93 \\
Ku70/80 & $0.76(0.38-1.50)$ & 0.42 &
\end{tabular}

that this difference can be explained by their individual characteristics and functions. DNA-PKcs appears to be restricted to higher eukaryotes, while $\mathrm{Ku} 70$ and Ku80 exist in organisms ranging from yeast to man (10). The function of Ligase IV is completely dependent on Ku but not on DNAPKcs, illustrating that the components of the DNA-PK complex have different functions (32). DNA-PKcs, by virtue of its kinase activity, belongs to a family of phosphatidyl- inositol 3-kinase-like protein kinases. It has the ability to phosphorylate itself in vivo on residue Thr2609 in response to DNA damage, and mutation of this residue leads to radiosensitivity and impaired rejoining of double-strand breaks (33).

In addition to its involvement in NHEJ repair, the kinase activity of DNA-PK also seems to be important in the signalling of DNA damage. The cellular response to DNA damage 
includes DNA repair, induction of apoptosis and cell cycle arrest. The tumour suppressor p53 is a key molecule in the coordination of these functions after genotoxic treatment. p53 is activated by several different kinases, including DNAPK (22). Although DNA-PK does not seem to be involved in communication with the cell cycle checkpoint machinery through p53, it appears that it has an important role in apoptotic signalling (34). Radiation-induced apoptosis in mouse thymocytes, which is mediated by $\mathrm{p} 53$, is suppressed in DNA-PKcs ${ }^{-/}$mice (35). In contrast, cell cycle arrest and p21-induction is normal in these cells. Similarly, IR-induced apoptosis in adenovirus E1A-sensitised mouse embryonic fibroblasts is abolished in the absence of DNA-PKcs (36). Taken together, these results indicate that phosphorylation of p53 by DNA-PK might selectively activate apoptotic pathways and that the kinase activity of DNA-PKcs is important in this aspect. Thus, it seems that in addition to its role in DNA repair, the DNA-PK complex can contribute to apoptosis as a response to ionising radiation, at least in cells with functioning $\mathrm{p} 53$. In this study, patients whose tumours had normal p53 benefitted from radiotherapy as compared to chemotherapy. Patients with altered p53 did not respond well to radiotherapy. When patients were divided into four subgroups according to the combined expression of p53 and DNA-PKcs, the benefit from radiotherapy was most evident in the subgroup of patients whose tumours had normal p53 combined with high expression of DNA-PKcs. The relative risk of recurrence (for patients treated with radiotherapy, as compared to chemotherapy-treated patients) in the subgroups was gradually increased if p53 was altered or DNA-PKcs expression low, and the highest when both these criteria were met. The number of patients in the different subgroups was however small, and the results should be interpreted with caution. This observation is in line with the findings discussed above that p53-mediated apoptosis induced by radiation is suppressed in cells with reduced DNA-PKcs levels. Similar results were obtained in a study on tonsillar carcinoma by Friesland et al, who found that among patients with p53 wild-type tumours, those who also had high levels of DNA-PKcs had longer survival times after radiotherapy than patients with low DNA-PKcs expression (28).

There are a handful of studies on the relationships between DNA-PKcs, Ku70, Ku80 and radiosensitivity in other tumour types, which have yielded different and sometimes contradicting results. Our results are supported by two different studies on cervical carcinoma, in which tumour response to radiotherapy and overall patient survival were better if the expression of Ku70 or Ku80 was low $(27,37)$. Similarly, there seems to be a correlation between low Ku70 expression and good histopathological response, as well as longer patient survival, after pre-operative radiotherapy in rectal cancer $(30,38)$. A recent study suggests that the DNA-PK complex is upregulated in cervical carcinoma cells surviving radiotherapy, indicating that upregulation of DNA-PK may be involved in radioresistance (39). Two studies have found no significant correlation between expression of the DNA-PK subunits and radiosensitivity $(31,40)$. In the current study, we found that high, rather than low expression, of DNA-PKcs was related to a good response to radiotherapy. This finding is in part similar to a study on squamous tonsillar carcinoma by Friesland et al, in which tumours with high expression of DNA-PKcs or Ku86 were more sensitive to radiotherapy (28).

These discrepancies between studies might in part be attributable to differences in tumour origin. Differences in the estimation of tumour radiosensitivity (e.g. in vitro measurements, tumour response in vivo, tumour control and patient survival) probably also contribute to disparities in the results and conclusions, and it is possible that the choice of antibodies also can affect the result. The antibodies used in this study have been employed in several other studies $(28,40,41)$. The expression of Ku70 and Ku80 are highly correlated when detected with immunohistochemistry and it has been shown that the stabilities of the two heterodimer components are dependent on each other in vitro $(27,42)$.

During the last decades the treatment of patients who have undergone breast cancer surgery has evolved greatly. Patients in the present study received CMF or radiotherapy, treatments that cannot be compared in terms of efficacy to the therapy offered today to breast cancer patients with the same clinical spread of the disease. The present study is randomised, which facilitates analysis of prognosis and prediction of treatment outcome as compared to the more complex, multimodality breast cancer treatment available today.

For the same study cohort, we have recently reported that low expression of the BRCA1/BRCA2/RAD51 complex in HR repair is associated with increased risk of local recurrence in early breast cancer (43). However, patients whose tumours had reduced levels of these proteins did also benefit from radiotherapy as compared to chemotherapy, suggesting that loss of this repair complex impairs the ability of the tumour cells to repair the radiation-induced damage correctly. In opposition to these findings, we have previously shown that maintained high expression of the proteins in the MRE11/ RAD50/NBS1 complex in tumour cells is related to good response to radiotherapy (26). Our finding that high expression of DNA-PKcs predicts good effect of radiotherapy is similar to this result, and if these results hold true in subsequent studies they could be an example of the intricate balance between repair, cell cycle arrest and cell death after radiation damage. Recently, a role for NBS1 in apoptosis induction following DNA damage was reported, and it was suggested that NBS1 promotes apoptosis by regulating the inhibitory Bax-Ku70 interaction (44). A dual role for these proteins in both DNA repair as well as cell death regulation might explain why high expression seems to be related to better response to radiotherapy.

The results from this study indicate that low expression of the $\mathrm{Ku}$ heterodimer, but high expression of DNA-PKcs, predict good effect of radiotherapy, and probably reflect the complexity of the networks that regulate the fate of a cell after exposure to ionising radiation. It would be important to keep this complexity in mind when developing individualised cancer treatments that target proteins in the DNA damage signalling and repair pathways.

\section{Acknowledgements}

We thank Najme Wall and Jan Olofsson for classifying the tumours according to the Nottingham grading system, and 
Lambert Skoog for sharing his great knowledge on breast tumour pathology. This work was supported by grants from the Swedish Cancer Society.

\section{References}

1. Clarke M, Collins R, Darby S, et al: Effects of radiotherapy and of differences in the extent of surgery for early breast cancer on local recurrence and 15-year survival: an overview of the randomised trials. Lancet 366: 2087-2106, 2005.

2. Xia F and Powell SN: The molecular basis of radiosensitivity and chemosensitivity in the treatment of breast cancer. Semin Radiat Oncol 12: 296-304, 2002.

3. Harrison L and Blackwell K: Hypoxia and anemia: factors in decreased sensitivity to radiation therapy and chemotherapy? Oncologist 9 (Suppl. 5): S31-S40, 2004

4. Pawlik TM and Keyomarsi K: Role of cell cycle in mediating sensitivity to radiotherapy. Int J Radiat Oncol Biol Phys 59: 928-942, 2004

5. Ross GM: Induction of cell death by radiotherapy. Endocr Relat Cancer 6: 41-44, 1999.

6. Steel GG: The case against apoptosis. Acta Oncol 40: 968-975, 2001

7. Leskov KS, Criswell T, Antonio S, et al: When X-ray-inducible proteins meet DNA double-strand break repair. Semin Radiat Oncol 11: 352-372, 2001

8. West SC: Molecular views of recombination proteins and their control. Nat Rev Mol Cell Biol 4: 435-445, 2003.

9. Mimori T, Hardin JA and Steitz JA: Characterization of the DNA-binding protein antigen $\mathrm{Ku}$ recognized by autoantibodies from patients with rheumatic disorders. J Biol Chem 261: 2274-2278, 1986

10. Smith GC and Jackson SP: The DNA-dependent protein kinase. Genes Dev 13: 916-934, 1999.

11. Gottlieb TM and Jackson SP: The DNA-dependent protein kinase: requirement for DNA ends and association with $\mathrm{Ku}$ antigen. Cell 72: 131-142, 1993.

12. Feng J, Park J, Cron P, Hess D and Hemmings BA: Identification of a PKB/Akt hydrophobic motif Ser-473 kinase as DNA-dependent protein kinase. J Biol Chem 279: 41189-41196, 2004.

13. Leber R, Wise TW, Mizuta R and Meek K: The XRCC4 gene product is a target for and interacts with the DNA-dependent protein kinase. J Biol Chem 273: 1794-1801, 1998

14. Blunt T, Finnie NJ, Taccioli GE, et al: Defective DNAdependent protein kinase activity is linked to $\mathrm{V}(\mathrm{D}) \mathrm{J}$ recombination and DNA repair defects associated with the murine scid mutation. Cell 80: 813-823, 1995.

15. Ouyang H, Nussenzweig A, Kurimasa A, et al: Ku70 is required for DNA repair but not for $\mathrm{T}$ cell antigen receptor gene recombination in vivo. J Exp Med 186: 921-929, 1997.

16. He F, Li L, Kim D, et al: Adenovirus-mediated expression of a dominant negative Ku70 fragment radiosensitizes human tumor cells under aerobic and hypoxic conditions. Cancer Res 67: 634-642, 2007.

17. Kim CH, Park SJ and Lee SH: A targeted inhibition of DNAdependent protein kinase sensitizes breast cancer cells following ionizing radiation. J Pharmacol Exp Ther 303: 753-759, 2002.

18. Shinohara ET, Geng L, Tan J, et al: DNA-dependent protein kinase is a molecular target for the development of noncytotoxic radiation-sensitizing drugs. Cancer Res 65: 4987-4992, 2005.

19. Zhao Y, Thomas HD, Batey MA, et al: Preclinical evaluation of a potent novel DNA-dependent protein kinase inhibitor NU7441. Cancer Res 66: 5354-5362, 2006.

20. Bozulic L, Surucu B, Hynx D and Hemmings BA: PKBalpha/ Akt1 acts downstream of DNA-PK in the DNA double-strand break response and promotes survival. Mol Cell 30: 203-213, 2008.

21. Cohen HY, Lavu S, Bitterman KJ, et al: Acetylation of the C terminus of Ku70 by CBP and PCAF controls Bax-mediated apoptosis. Mol Cell 13: 627-638, 2004.

22. Woo RA, McLure KG, Lees-Miller SP, Rancourt DE and Lee PW: DNA-dependent protein kinase acts upstream of p53 in response to DNA damage. Nature 394: 700-704, 1998.

23. Hainaut P, Hernandez T, Robinson A, et al: IARC database of p53 gene mutations in human tumors and cell lines: updated compilation, revised formats and new visualisation tools. Nucleic Acids Res 26: 205-213, 1998.
24. Cuddihy AR and Bristow RG: The p53 protein family and radiation sensitivity: Yes or no? Cancer Metastasis Rev 23: 237-257, 2004

25. Rutqvist LE and Johansson H: Long-term follow-up of the Stockholm randomized trials of postoperative radiation therapy versus adjuvant chemotherapy among high risk pre- and postmenopausal breast cancer patients. Acta Oncol 45: 517-527, 2006.

26. Soderlund K, Stal O, Skoog L, Rutqvist LE, Nordenskjold B and Askmalm MS: Intact Mre11/Rad50/Nbs1 complex predicts good response to radiotherapy in early breast cancer. Int J Radiat Oncol Biol Phys 68: 50-58, 2007.

27. Wilson CR, Davidson SE, Margison GP, Jackson SP, Hendry JH and West CM: Expression of Ku70 correlates with survival in carcinoma of the cervix. Br J Cancer 83: 1702-1706, 2000.

28. Friesland S, Kanter-Lewensohn L, Tell R, Munck-Wikland E, Lewensohn R and Nilsson A: Expression of Ku86 confers favorable outcome of tonsillar carcinoma treated with radiotherapy. Head Neck 25: 313-321, 2003.

29. Saygili U, Gorkay IB, Koyuncuoglu M, Gol M, Uslu T and Erten O: The relationship between expression of Ku70 and survival in irradiated patients with endometrial carcinoma. Gynecol Oncol 95: 518-522, 2004.

30. Komuro Y, Watanabe T, Hosoi Y, et al: The expression pattern of $\mathrm{Ku}$ correlates with tumor radiosensitivity and disease-free survival in patients with rectal carcinoma. Cancer 95: 1199-1205, 2002.

31. Beskow C, Kanter L, Holgersson A, et al: Expression of DNA damage response proteins and complete remission after radiotherapy of stage IB-IIA of cervical cancer. Br J Cancer 94: 1683-1689, 2006

32. Adachi N, Ishino T, Ishii Y, Takeda S and Koyama H: DNA ligase IV-deficient cells are more resistant to ionizing radiation in the absence of Ku70: Implications for DNA double-strand break repair. Proc Natl Acad Sci USA 98: 12109-12113, 2001.

33. Chan DW, Chen BP, Prithivirajsingh S, et al: Autophosphorylation of the DNA-dependent protein kinase catalytic subunit is required for rejoining of DNA double-strand breaks. Genes Dev 16: 2333-2338, 2002 .

34. Jimenez GS, Bryntesson F, Torres-Arzayus MI, et al: DNAdependent protein kinase is not required for the p53-dependent response to DNA damage. Nature 400: 81-83, 1999.

35. Wang S, Guo M, Ouyang H, et al: The catalytic subunit of DNA-dependent protein kinase selectively regulates p53dependent apoptosis but not cell-cycle arrest. Proc Natl Acad Sci USA 97: 1584-1588, 2000.

36. Woo RA, Jack MT, Xu Y, Burma S, Chen DJ and Lee PW: DNA damage-induced apoptosis requires the DNA-dependent protein kinase, and is mediated by the latent population of $\mathrm{p} 53$. EMBO J 21: 3000-3008, 2002.

37. Harima Y, Sawada S, Miyazaki Y, et al: Expression of Ku80 in cervical cancer correlates with response to radiotherapy and survival. Am J Clin Oncol 26: e80-e85, 2003.

38. Komuro Y, Watanabe T, Hosoi Y, et al: Prediction of tumor radiosensitivity in rectal carcinoma based on p53 and Ku70 expression. J Exp Clin Cancer Res 22: 223-228, 2003.

39. Beskow C, Skikuniene J, Holgersson A, et al: Radioresistant cervical cancer shows upregulation of the NHEJ proteins DNAPKcs, Ku70 and Ku86. Br J Cancer 101: 816-821, 2009.

40. Bjork-Eriksson T, West C, Nilsson A, et al: The immunohistochemical expression of DNA-PKCS and $\mathrm{Ku}(\mathrm{p} 70 / \mathrm{p} 80)$ in head and neck cancers: relationships with radiosensitivity. Int $J$ Radiat Oncol Biol Phys 45: 1005-1010, 1999.

41. Sakata K, Matsumoto Y, Tauchi H, et al: Expression of genes involved in repair of DNA double-strand breaks in normal and tumor tissues. Int J Radiat Oncol Biol Phys 49: 161-167, 2001.

42. Satoh M, Wang J and Reeves WH: Role of free p70 (Ku) subunit in posttranslational stabilization of newly synthesized p80 during DNA-dependent protein kinase assembly. Eur J Cell Biol 66: 127-135, 1995.

43. Soderlund K, Skoog L, Fornander T and Askmalm MS: The BRCA1/BRCA2/Rad51 complex is a prognostic and predictive factor in early breast cancer. Radiother Oncol 84: 242-251, 2007.

44. Iijima K, Muranaka C, Kobayashi J, et al: NBS1 regulates a novel apoptotic pathway through Bax activation. DNA Repair (Amst) 7: 1705-1716, 2008. 